\title{
Evolution and investigation of copper and gold ball bonds in extended reliability stressing
}

\author{
C. L. Gan • F. C. Classe • B. L. Chan • U. Hashim
}

Published online: 29 March 2014

(C) The Author(s) 2014. This article is published with open access at SpringerLink.com

\begin{abstract}
This paper discusses the microstructure evolution of copper $(\mathrm{Cu})$ and gold $\mathrm{(Au}$ ) ball bonds after various extended reliability stresses such as biased highly accelerated temperature and humidity test (HAST), unbiased highly accelerated temperature and humidity test (UHAST), temperature cycling (TC), and high temperature storage life (HTSL) in BGA package. Objective of this study is to study the microstructure evolution and changes after long hours and long cycles of component reliability stressing and its predicted failure mechanisms and to determine the long-term reliability comparison with combination of bonding wires in HAST, UHAST, and TC. Secondary electron microscopy (SEM) and energy dispersive X-ray (EDX) have been carried out to understand the respective microstructure of failed samples in HAST, UHAST, TC, and HTSL long-term reliability failures. Respective failure mechanisms of copper and gold ball bonds carrion under HAST and UHAST, ball bond lifting in TC and HTSL have been analyzed and proposed. The evolution of surface morphology, including copper and gold ball bond micro cracking, gold ball bond Kirkendall microvoiding and intermetallic compound (IMC) formation, was studied in FBGA package with copper and gold ball bonds during various reliability stresses. Biased HAST, UHAST, TC, and HTSL mechanisms were proposed to explain the observed morphological changes and the resulting ball bond wear out modes after extended reliability stresses. Weibull reliability analyses have been established to compare the performance of
\end{abstract}

C. L. Gan $(\bowtie) \cdot$ F. C. Classe • B. L. Chan

Spansion (Penang) Sdn Bhd, Phase II Free Industrial Zone,

Penang 11900 Bayan Lepas, Malaysia

e-mail: chong-leong.gan@spansion.com

C. L. Gan • U. Hashim

Institute of Nanoelectronic Engineering (INEE), Universiti Malaysia

Perlis, Perlis 01000, Kangar, Malaysia copper and gold ball bonds under humid and dry environmental tests.

Keywords Microstructure evolution - Copper and gold ball bonds $\cdot$ Failure mechanisms $\cdot$ SEM $\cdot$ EDX analysis $\cdot$ Extended reliability $\cdot$ Weibull plot

\section{Introduction}

Gold and copper wire bondings are two most common bonding techniques used in microelectronic packaging in semiconductor industry. Recently, copper wire bonding appears to be the alternate materials and various engineering studies on copper wire development have been reported [1]. Technical barriers and reliability challenges of $\mathrm{Cu}$ wire bonding in microelectronics packaging are well identified [2-11]. Au-Al microstructure evolution and intermetallic compound (IMC) formation is widely studied by Karpel et al. [12]. Two types of failures occurred during annealing: crack formation at the bond periphery due to an increase in volume during intermetallic growth and the formation of stresses; and oxidation of the $\mathrm{AlAu}_{4}$ phase adjacent to the $\mathrm{Au}$ ball, which resulted in the formation of continuous cracks between the Au ball and the intermetallic region [10]. Drozdov et al. [13, 14] evaluated CuAl IMC formation on as-bonded stage and post annealing to study the interface composition and morphology of copper wire bonds heat-treated at $175{ }^{\circ} \mathrm{C}$ for $2,24,96$, and $200 \mathrm{~h}$ in argon. The main intermetallic phase was $\mathrm{Al}_{2} \mathrm{Cu}$, which was found to grow via solid state diffusion. In specimens heat-treated for 96 and $200 \mathrm{~h}$, the $\mathrm{Al}_{4} \mathrm{Cu}_{9}$ phase was also detected. Void formation at the $\mathrm{Al}-\mathrm{Cu}$ bonds heat-treated up to $200 \mathrm{~h}$ was not found to be a source of bond failure. $\mathrm{Xu} \mathrm{C}$ et al. [15] studied oxidation behavior of two types of bulk gold aluminides, $\mathrm{AuAl}_{2}$, and $\mathrm{Au}_{4} \mathrm{Al}$, using thermogravimetry. $\mathrm{Xu} \mathrm{H}$ et al. $[16,17]$ characterized behavior of aluminum oxide, intermetallics, and voids in 
$\mathrm{Cu}-\mathrm{Al}$ wire bonds. Zeng Y et al. [18] plotted Pourbaix (Eh-pH) diagrams of $\mathrm{Al}-\mathrm{Cu}$ alloys (instead of pure metals) are generated on the basis of critical assessment of thermodynamic data. The Eh-pH diagram is used to conduct comprehensive studies on the thermodynamic equilibrium of $\mathrm{Cu}-\mathrm{Al}$ bonding at humid environment with chlorine.

$\mathrm{Cu}$ ball bond is more susceptible to moisture corrosion compared to gold ball bonds and undergo different corrosion mechanisms in microelectronic packaging [19-21]. There are different ball bonds corrosion mechanisms of $\mathrm{Au}$ and $\mathrm{Cu}$ ball bond under humid reliability test. Uno $\mathrm{T}[21]$ reported $\mathrm{CuAl}$ IMC interfacial corrosion under HAST environmental test. Yamaji Y et al. [22] and Su P et al. [23] reported similar $\mathrm{CuAl}$ IMC interfacial corrosion post HAST and UHAST tests and effects of $\mathrm{pH}$ of molding compounds on HAST failure rates. $\mathrm{Lu}$ YH et al. [24] observed the growth rates of IMCs in $\mathrm{Pd}$-coated $\mathrm{Cu}$ wire bonds are very sensitive to temperature, but the sequence of IMC formation remains the same for temperature below $350{ }^{\circ} \mathrm{C}$. Pd atoms in the Pd-coated $\mathrm{Cu}$ wire do not participate in the interfacial reaction, and have no marked effect on the growth rate of IMCs. Gan et al. conducted studies on effects of bonding wires on UHAST and TC reliability and found Au with better UHAST reliability compare to $\mathrm{Cu}$ wire [25-31]. Au ball bond is well known with its $\mathrm{Au}$ atomic diffusion into $\mathrm{Al}$ metallization and caused resistive ball bonds with non-optimized bonding parameter [1, 25]. The interdiffusion between $\mathrm{Au}$ and $\mathrm{Al}$ across a thermally exposed $\mathrm{Au}-\mathrm{Al}$ ball bond causes the movement of the void line towards the Au bump and shows that Au interdiffuses faster than Al. Although the movement of the void line appears to be associated with movement of the $\mathrm{Au}_{4} \mathrm{Al}$ or $\mathrm{Au}_{8} \mathrm{Al}_{3}$ interface, it is actually analogous to the Kirkendall microvoiding. $\mathrm{Yu} \mathrm{CH}$ et al. [32] studied HTSL failure mechanism of $\mathrm{Cu}$ ball bond after aging at $205^{\circ} \mathrm{C}$ in air from $0 \mathrm{~h}$ to $2,000 \mathrm{~h}$. The cracks grew towards the ball bond center with an increase in the aging time, and the $\mathrm{Cl}$ ions diffused through the crack into the ball center. This diffusion caused a corrosion reaction between the $\mathrm{Cl}$ ions and the $\mathrm{Cu}-\mathrm{Al}$ intermetallic phases, which in turn caused copper wire bonding damage [32].

\section{Experimental procedures}

Specimen preparation

Copper wires were bonded on top of silicon wafers coated with thermally grown $\mathrm{SiO}_{2}$ and covered by uniform aluminum (Al) metallization. The $\mathrm{Al}$ metallization consisted of $0.5 \mathrm{wt} \%$ $\mathrm{Cu}$ and $1 \mathrm{wt} \% \mathrm{Si}$. Materials used include 0.8 mil Pd-coated $\mathrm{Cu}$ wire $(\mathrm{Cu})$ and $4 \mathrm{~N}$ (99.99\% purity) gold (Au) wire, $90 \mathrm{~nm}$ and $110 \mathrm{~nm}$ flash devices packaged into fortified fine-pitch BGA packages, with green $(<20 \mathrm{ppm}$ chloride in content) molding compound and substrate. Thermosonic ball bonding of each
Si die was performed at $175^{\circ} \mathrm{C}$ for an approximate time of $18 \mathrm{~s}$ per device with a pre-heat and post-heat of $18 \mathrm{~s}$ at $150^{\circ} \mathrm{C}$. The bonding parameters were optimized to ensure zero pad peals, which is an essential condition for successful copper wire bonding. In order to ensure uniform and symmetric bonds, free air balls at the $\mathrm{Cu}$ wire tip were formed by melting the tips of the $\mathrm{Cu}$ wires in a reducing atmosphere ( $95 \% \mathrm{~N}_{2}, 5 \% \mathrm{H}_{2}$ ) prior to the bonding stage.

The corresponding stress tests and its conditions are tabulated in Table 1. Extended reliability stresses include biased HAST $\left(130^{\circ} \mathrm{C}, 85 \% \mathrm{RH}, 3.60 \mathrm{~V}\right.$ biasing voltage), unbiased HAST $\left(130{ }^{\circ} \mathrm{C}, 85 \% \mathrm{RH}\right)$, temperature cycling $\left(-40^{\circ} \mathrm{C}\right.$ to $\left.150{ }^{\circ} \mathrm{C}\right)$, and $\operatorname{HTSL}\left(150^{\circ} \mathrm{C}\right.$ and $\left.200^{\circ} \mathrm{C}\right)$. All direct material used in this evaluation study for the $90 \mathrm{~nm}$ and $110 \mathrm{~nm}$, flash device (with top $\mathrm{Al}$ metallization bondpad) for packaging purpose. Forty-five units of $\mathrm{Au}$ and $\mathrm{Pd}$-coated $\mathrm{Cu}$ wire bonded on fine-pitch 64-ball BGA packages are subjected for $150^{\circ} \mathrm{C}$ aging temperature. Electrical testing was conducted after each hours and cycles of stress to check $\mathrm{Au}$ and $\mathrm{Cu}$ ball bond integrity in terms of its high temperature ball bonds reliability with various aging conditions. The package construction of test vehicle, FBGA 64 as depicted in Fig. 1, is assembled with gold or copper wires.

Prior to biased HAST, UHAST and TC stresses, the electronic packages were subjected to preconditioning $\left(30{ }^{\circ} \mathrm{C}\right.$, $60 \% \mathrm{RH}$ ) for $192 \mathrm{~h}$ in a temperature and humidity chamber, followed by three cycles of reflow at $260{ }^{\circ} \mathrm{C}$ by using reflow chamber as per JEDEC IPC-STD 020 [35]. After preconditioning and electrical test, samples were loaded in respective HAST, UHAST, and TC chambers according to the stress conditions as tabulated in Table 1. After each read point, electrical opens, shorts, and device datasheet functionality was verified by using a commercial electrical tester. $\mathrm{Cu}$ and Au ball bonds microstructure analysis were measured by using secondary electron microscopy (SEM) to understand the morphology and microstructure evolution. Composition analysis on failed samples were determined by using energy dispersive X-ray (EDX) on FBGA 64 package with different sets of extended reliability stresses. Wear out reliability tests were conducted on HAST, UHAST, and TC package reliability stresses to predict its reliability margins of $\mathrm{Au}$ and $\mathrm{Cu}$ wires used in FBGA package. The time and cycles-to-failures reliability modeling can be predicted based on the stress-to-failures in respective reliability stresses [33].

Table 1 Summary of extended reliability matrix (for $\mathrm{Au}$ and $\mathrm{Cu}$ wires)

\begin{tabular}{lll}
\hline Extended reliability stresses & Test conditions & Sample size \\
\hline Biased HAST & $85 \% \mathrm{RH}, 110^{\circ} \mathrm{C}, 3.6 \mathrm{~V}$ & 80 \\
Unbiased HAST & $85 \% \mathrm{RH}, 130^{\circ} \mathrm{C}$ & 80 \\
TC & $-40{ }^{\circ} \mathrm{C}$ to $150{ }^{\circ} \mathrm{C}$ & 80 \\
HTSL & $150{ }^{\circ} \mathrm{C}, 200{ }^{\circ} \mathrm{C}$ & 45 \\
\hline
\end{tabular}




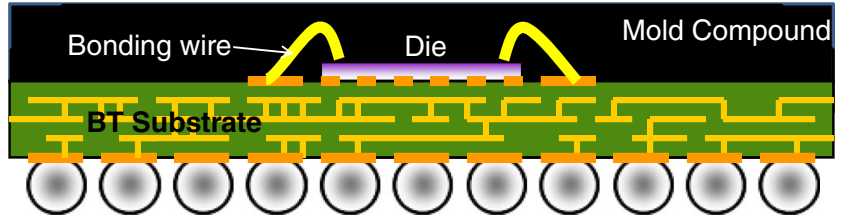

Fig. 1 FBGA 64 package constructions with $\mathrm{Cu}$ and $\mathrm{Au}$ wires used in reliability sample preparation

\section{Result and discussion}

Ball bond corrosion under highly humidity and temperature test

\section{Biased HAST test}

In order to obtain information regarding the $\mathrm{Al}-\mathrm{Cu}$ interface composition after HAST or UHAST tests, $\mathrm{CuAl}$ and AuAl samples were studied using EDX. EDX analysis was conducted using FEI Tecnai microscopes, following the standard procedure. In order to ensure acquisition of the signal from a selected region, the specimen was tilted $15^{\circ}$ towards the EDX detector. Typical CuAl IMC microcracking is found for the HAST 2,000 h electrical open failure (see Fig. 2).

Figure 3 shows representative SEM cross section and EDX analysis of failed $\mathrm{Cu}$ ball bond. EDX analysis on the micro crack at the edge of $\mathrm{Cu}$ ball bond indicates presence of $\mathrm{O}$ and $\mathrm{Cl}$ peaks. This proves the hydrolysis of $\mathrm{CuAl}$ IMC under UHAST moist conditions and $\mathrm{Cl}$ peak is originated from $\mathrm{AlCl}_{3}$. The trace $\mathrm{Cl}^{-}$is usually found in epoxy mold compound. Tables 2 and 3 tabulates the summary of EDX analysis of $\mathrm{Au}$ and $\mathrm{Cu}$ ball bonds.

Figure 4 reveals SEM micrograph of HAST 2,000 h open found on $\mathrm{Au}$ ball bond and presents SEM micrographs taken the periphery of a bond subjected for HAST 2,000 h. The intermetallic coverage of the $\mathrm{Au}-\mathrm{Cu}$ interface is not complete. Regions at the interface with no intermetallics can still be found. The intermetallics found at the bond periphery are less uniform than those found along the whole gold ball bonds. The intermetallics found at the left side of gold ball bond are more continuous. Voiding between the gold ball and the intermetallics located at the bond periphery can be detected. EDX analysis (in Table 2) confirmed presence of $\mathrm{O}$ peak and this might be induced by hydrolysis of $\mathrm{Au}_{4} \mathrm{Al}$ into $\mathrm{Al}_{2} \mathrm{O}_{3}$ (see Eq. 3).

\section{Unbiased HAST test}

UHAST test is pretty similar to biased HAST test except is without biasing condition $\left(85 \% \mathrm{RH}, 130{ }^{\circ} \mathrm{C}\right)$. Corrosion is typically found after long hours of UHAST test. Figure 5 presents SEM micrograph of failed $\mathrm{Cu}$ ball bond (electrical open) after $3,000 \mathrm{~h}$ of UHAST stress. EDX analysis on failing $\mathrm{Cu}$ ball bond shows higher percentage of $\mathrm{O}$ and $\mathrm{Cl}$ peaks compared to good ball bond (see Table 2). The source of $\mathrm{Cl}^{-}$could be originating from the non-green molding compound used in assembly of FBGA 64 and corroded the $\mathrm{Cu}$ ball bond under highly temperature and humidity stresses such as UHAST or HAST.
Fig. $2 \mathrm{Cu}$ ball bond corrosion found after biased HAST 2,000 h. $\mathrm{CuAl}$ IMC interface microcracking found beneath $\mathrm{Cu}$ ball bond in extended hours of HAST failure
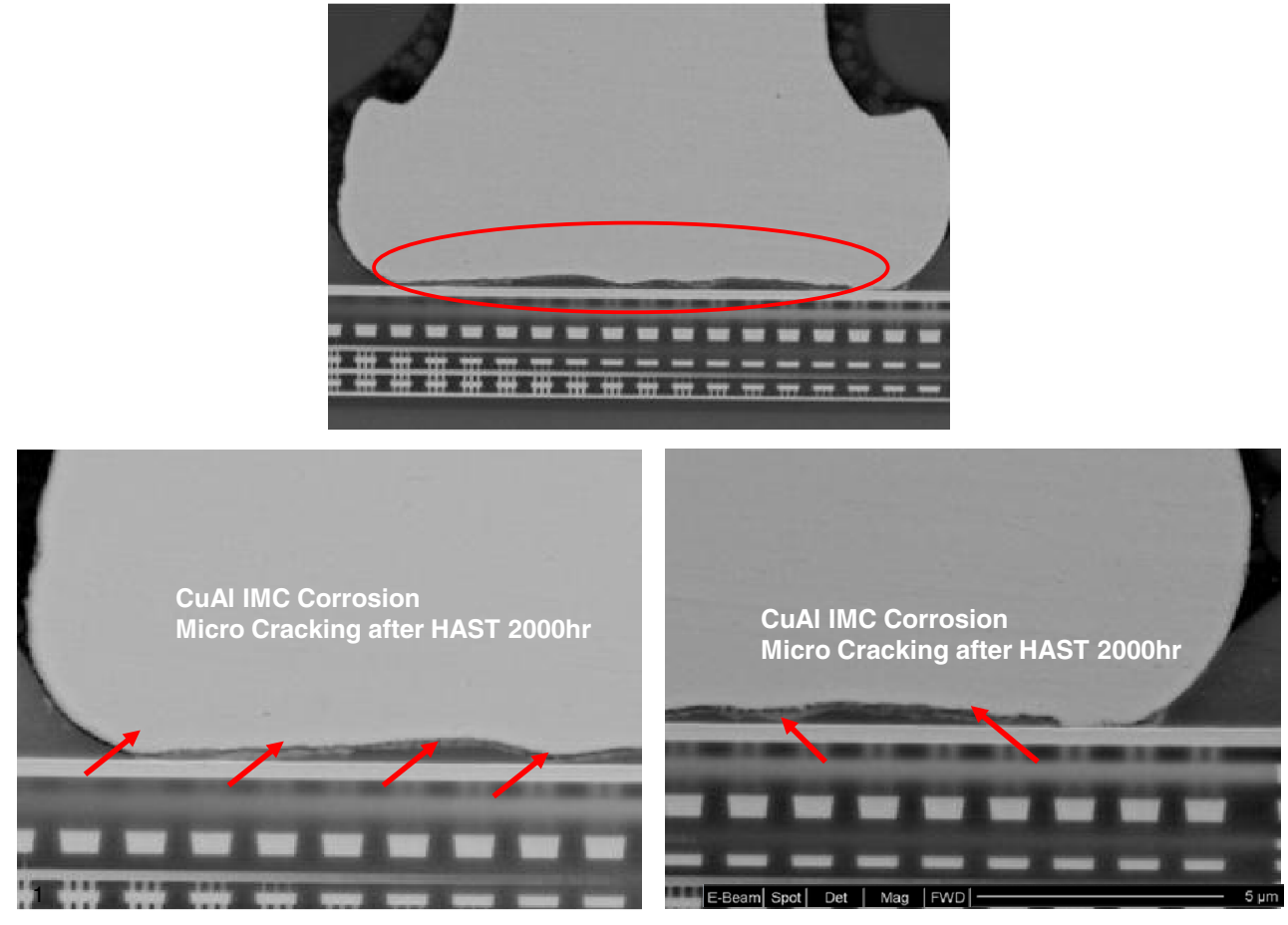
Fig. 3 EDX analysis shows presence of $\mathrm{Cl}^{-}$content at the $\mathrm{CuAl}$ IMC interfacial microcracking region. $\mathrm{Cu}$ ball bond corrosion found after biased HAST 2,000 h

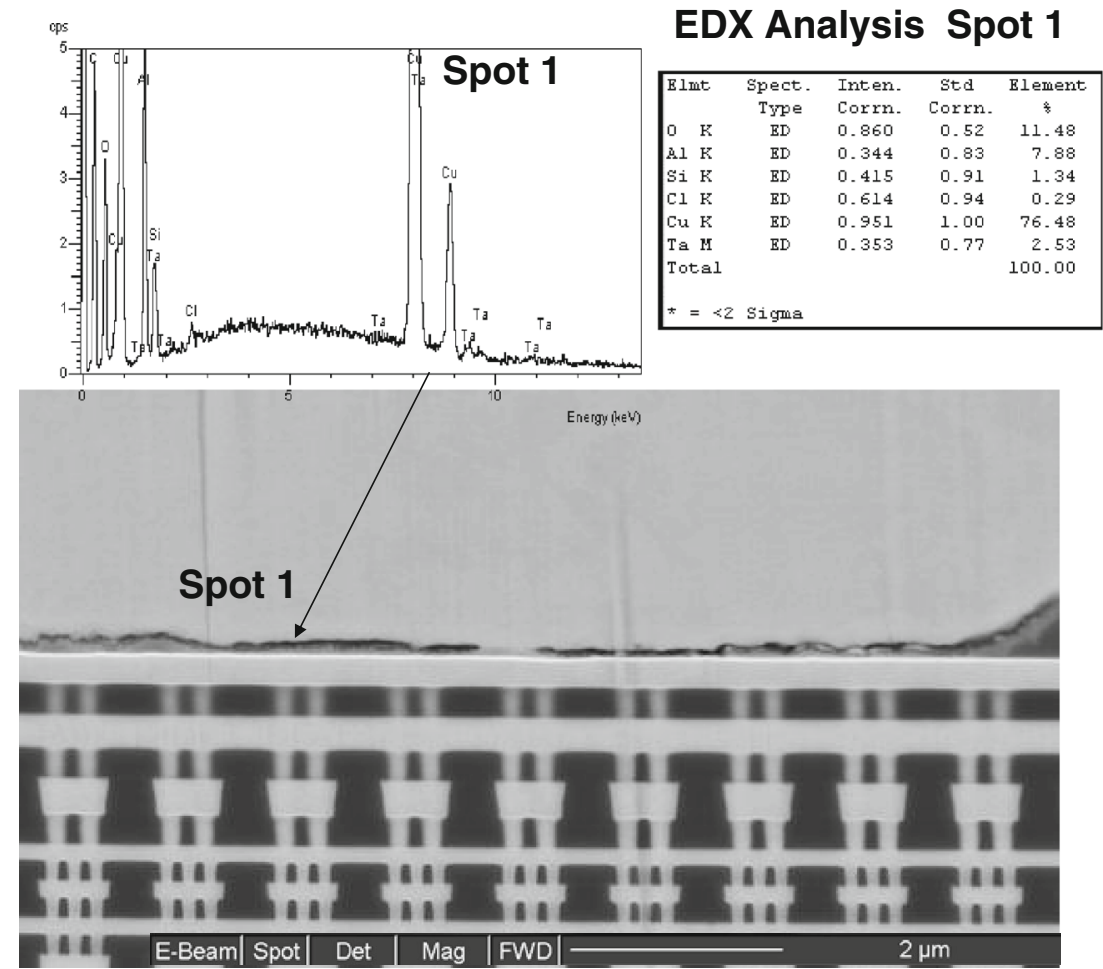

Ball bond microcracking under dry environmental stress

\section{Temperature cycling test}

Figure 6a presents SEM micrograph of CuAl IMC microcracking after undergoing extended temperature cycling (TC) stress of 9,500 cycles of $-40{ }^{\circ} \mathrm{C}$ to $150{ }^{\circ} \mathrm{C}$. Obvious molding compound to die passivation delamination is observed across the row of failing $\mathrm{Cu}$ ball bonds. This indicates the mismatches of coefficient of thermal expansion (CTE) between molding compound and silicon die which induced the CuAl IMC microcracking after extended cycles of TC. Figure $6 \mathrm{~b}$ shows closed up failed $\mathrm{Cu}$ ball bond after TC 9,500 cycles and full separation of $\mathrm{CuAl}$ IMC beneath $\mathrm{Cu}$ ball bond. EDX analysis on site 1 and site 2 near the $\mathrm{CuAl}$ IMC interfacial microcracking shows presence of $\mathrm{C}, \mathrm{Cu}, \mathrm{O}, \mathrm{Si}$, and $\mathrm{Al}$ elements without $\mathrm{Cl}^{-}$element (see Fig. 6b). Table 4 tabulates the EDX analysis comparing failing $\mathrm{Au}$ and $\mathrm{Cu}$ ball bond after TC 9,500 cycles.

Table 2 EDX analysis of failed $\mathrm{Cu}$ and $\mathrm{Au}$ ball bonds after HAST $2,000 \mathrm{~h}$ open failures

\begin{tabular}{lllllllll}
\hline Sample & \multicolumn{6}{l}{ Element (atomic \%) } \\
\cline { 2 - 8 } & $\mathrm{Au}$ & $\mathrm{Cu}$ & $\mathrm{O}$ & $\mathrm{Al}$ & $\mathrm{Si}$ & $\mathrm{Ta}$ & $\mathrm{Cl}$ \\
\hline Au ball & 32.15 & - & 24.76 & 43.15 & - & - & - \\
$\mathrm{Cu}$ ball & - & 76.48 & 11.48 & 7.88 & 1.34 & 2.53 & 0.29 \\
\hline
\end{tabular}

High temperature storage life test

Specimens heat-treated in nitrogen for more than 3,000 hat $150{ }^{\circ} \mathrm{C}$ Figure $7 \mathrm{a}$, b presents SEM micrographs of failed $\mathrm{Cu}$ ball bonds after aged for $3,500 \mathrm{~h}$ at $150{ }^{\circ} \mathrm{C}$. We found $\mathrm{CuAl}$ IMC full separation and microcracking along beneath $\mathrm{Cu}$ ball bonds at the edge and also center regions of $\mathrm{CuAl}$ IMC. EDX area scan reveals presence of $\mathrm{O}, \mathrm{Al}, \mathrm{Si}$, and $\mathrm{Cu}$ elements at the edge of failed $\mathrm{Cu}$ ball bond. No signature of halide element such as $\mathrm{Cl}$ (see Fig. 7c) since HTSL is conducted in a dry environmental chamber with nitrogen purging gas.

Figure 8 indicates the uneven AuAl IMC layer formation after aging for $3,500 \mathrm{~h}$ at $150{ }^{\circ} \mathrm{C}$. The SEM micrographs show the Au HTSL 3,500 h opens. Variation of thicknesses of AuAl IMCs is noted due to the faster $\mathrm{Au}$ atom diffusion into $\mathrm{Al}$ metallization on Al bondpad. Hence, thicker AuAl IMC will be found in HTSL stress, and Kirkendall microvoiding is observed after long aging time in Au ball bonds (see Fig. 8).

Representative EDX analysis of failed $\mathrm{Cu}$ and $\mathrm{Au}$ ball bonds after $3,500 \mathrm{~h}$ of HTSL at $150^{\circ} \mathrm{C}$ is shown in Table 5

Table 3 EDX analysis of failed $\mathrm{Cu}$ and good $\mathrm{Cu}$ ball bonds after UHAST $3,000 \mathrm{~h}$

\begin{tabular}{|c|c|c|c|c|c|c|c|}
\hline \multirow[t]{2}{*}{ Sample } & \multicolumn{7}{|c|}{ Element (atomic \%) } \\
\hline & $\mathrm{Au}$ & $\mathrm{Cu}$ & $\mathrm{O}$ & $\mathrm{Al}$ & $\mathrm{Si}$ & $\mathrm{Ta}$ & $\mathrm{Cl}$ \\
\hline Good $\mathrm{Cu}$ ball & - & 83.14 & 1.48 & 11.02 & 0.98 & 3.38 & - \\
\hline Failed $\mathrm{Cu}$ ball & - & 78.28 & 8.64 & 8.17 & 1.89 & 2.40 & 0.68 \\
\hline
\end{tabular}


Fig. $4 \mathrm{Au}$ ball bond corrosion found after biased HAST 2,000 h. Thicker AuAl IMC is formed unevenly beneath $\mathrm{Au}$ ball bond. Microcracking is observed between $\mathrm{Au}$ ball bond and $\mathrm{AuAl}$ IMC. EDX analysis reveals presence of $\mathrm{Au}, \mathrm{O}$, and $\mathrm{Al}$ elements
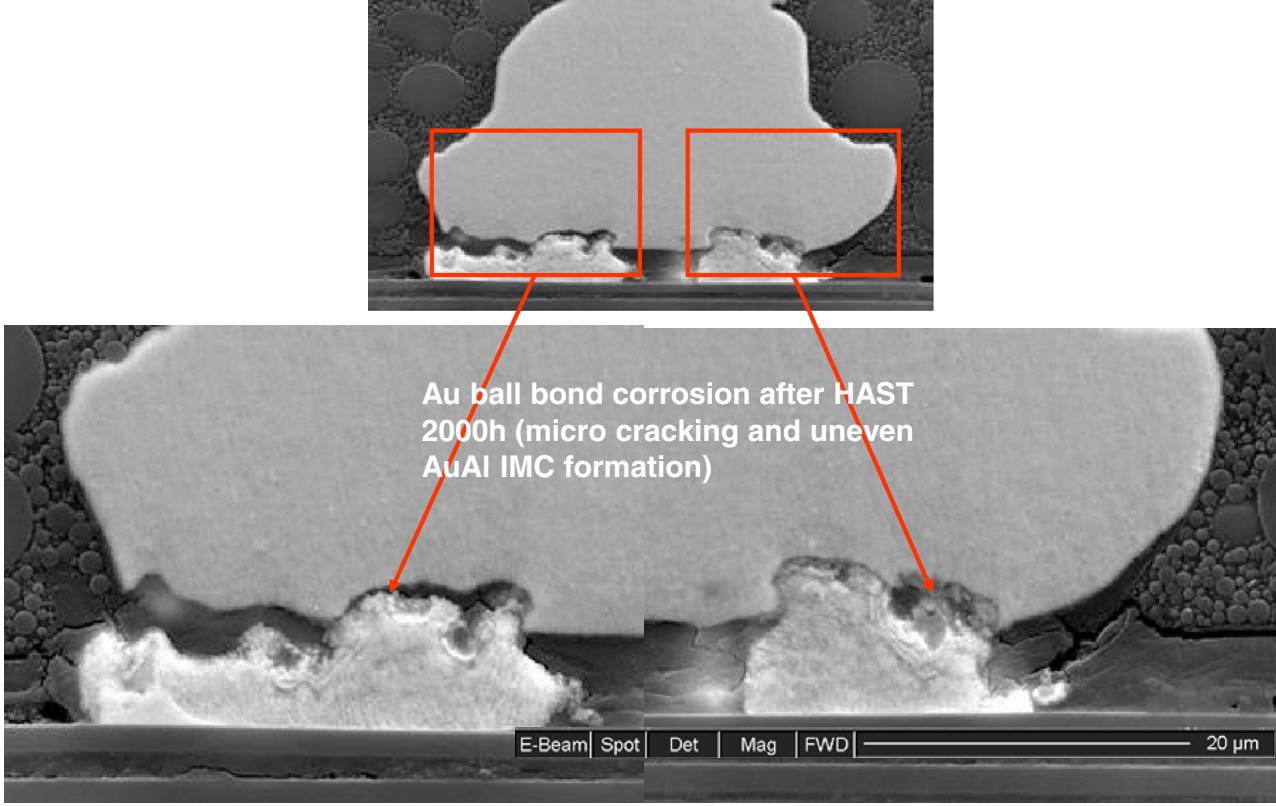

whereby no presence of $\mathrm{Cl}^{-}$ion in both failing $\mathrm{Au}$ and $\mathrm{Cu}$ ball bonds. This is noted as HTSL test is conducted in a dry environment condition at $150^{\circ} \mathrm{C}$. As noted in our previous report [34, 35], discontinuous intermetallics were found in aged HTSL specimens on $\mathrm{Au}$ and $\mathrm{Cu}$ ball bonds. The predicted HTSL wear out mechanisms are illustrated in Fig. 11.

$\mathrm{Cu}$ and $\mathrm{Au}$ ball bond corrosion (biased HAST and unbiased HAST)

$\mathrm{CuAl}$ IMC growth mechanism is slightly different from $\mathrm{AuAl}$ IMC in microelectronic packages. The IMC between $\mathrm{Cu}$ wire and $\mathrm{Al}$ pad can be distinguished into five types, as in the case of $\mathrm{Au}$ wire. However, only two IMC, $\mathrm{Cu}_{9} \mathrm{Al}_{4}$ and $\mathrm{CuAl}_{2}$, can be typically observed because the $\mathrm{CuAl}$ IMC forms very slowly and it is very thin in $\mathrm{Cu}$ ball bond IMC growth. $\mathrm{CuAl}$ IMC will be formed thicker at the edge of $\mathrm{Cu}$ ball bond compared to the center of $\mathrm{Cu}$ ball bond. This is mainly due to the thermo- compression effect during capillary compression onto $\mathrm{Al}$ bondpad during wire bonding induced by capillary compression.

Moisture in HAST or UHAST chamber will attack $\mathrm{Cu}$ ball bond at both edges of $\mathrm{Cu}$ ball bonds. Trace $\mathrm{Cl}^{-}$ion from molding compound will corrode the thin $\mathrm{CuAl}$ IMC layer beneath $\mathrm{Cu}$ ball bond and hydrolysis of $\mathrm{CuAl}$ IMC will occur (see Eq. 1). CuAl IMC microcracking will occur as a result of hydrogen outgassing or embrittlement (as in Eq. 2). Hydrolysis of CuAl IMC will form a brittle IMC, still conductive in $\mathrm{Cu}$ ball bond but resistive and will reach wear out opens (lifted ball bond after corrosion) after extended reliability stressing under HAST or UHAST (see Fig. 9).

$\mathrm{Cu}_{9} \mathrm{Al}_{4}+6 \mathrm{H}_{2} \mathrm{O} \rightarrow 2\left(\mathrm{Al}_{2} \mathrm{O}_{3}\right)+6 \mathrm{H}_{2}+9 \mathrm{Cu}$ (out gassing)

$\mathrm{CuAl}_{2}+3 \mathrm{H}_{2} \mathrm{O} \rightarrow \mathrm{Al}_{2} \mathrm{O}_{3}+\mathrm{Cu}$

$+3 \mathrm{H}_{2}$ (out gassing which mightcause IMC cracks)
Fig. $5 \mathrm{Cu}$ ball bond corrosion found after unbiased HAST $3,000 \mathrm{~h}$. Microcracking is observed at the edge of $\mathrm{Cu}$ ball bond region. EDX analysis reveals presence of $\mathrm{Cu}, \mathrm{O}, \mathrm{Cl}$, and Al elements
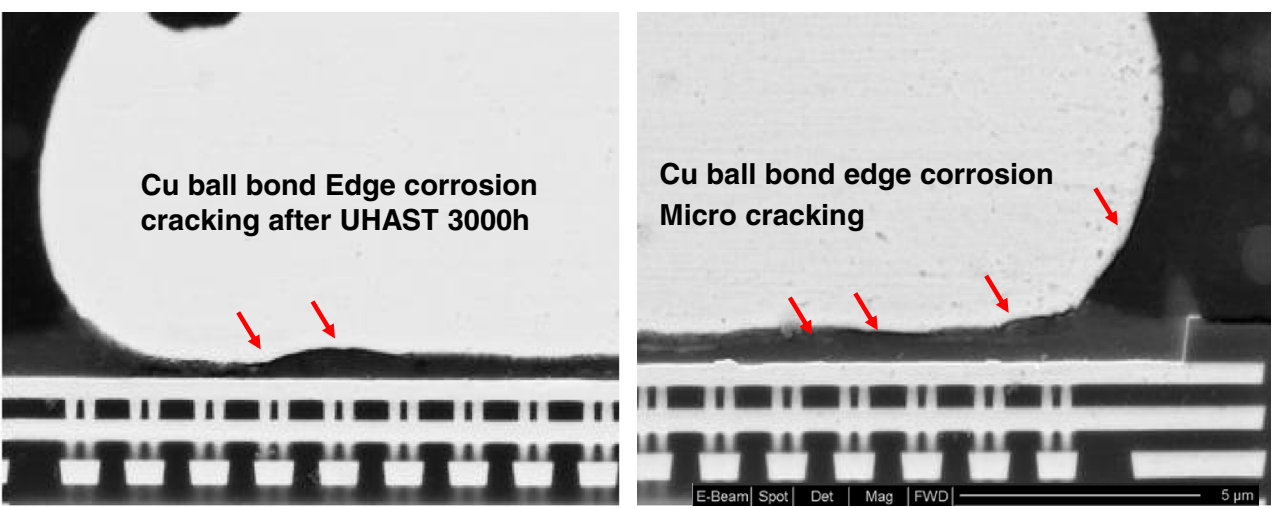
Fig. $6 \mathrm{Cu}$ ball bond microcracking is observed after TC 9,500 cycles (a). Mold compound to die interfacial delamination is found and might be the factor induced $\mathrm{CuAl}$ IMC microcracking. EDX analyses reveal presence of $\mathrm{C}, \mathrm{Cu}, \mathrm{O}, \mathrm{Si}$, and $\mathrm{Al}$ elements without $\mathrm{Cl}^{-}$ element (b)
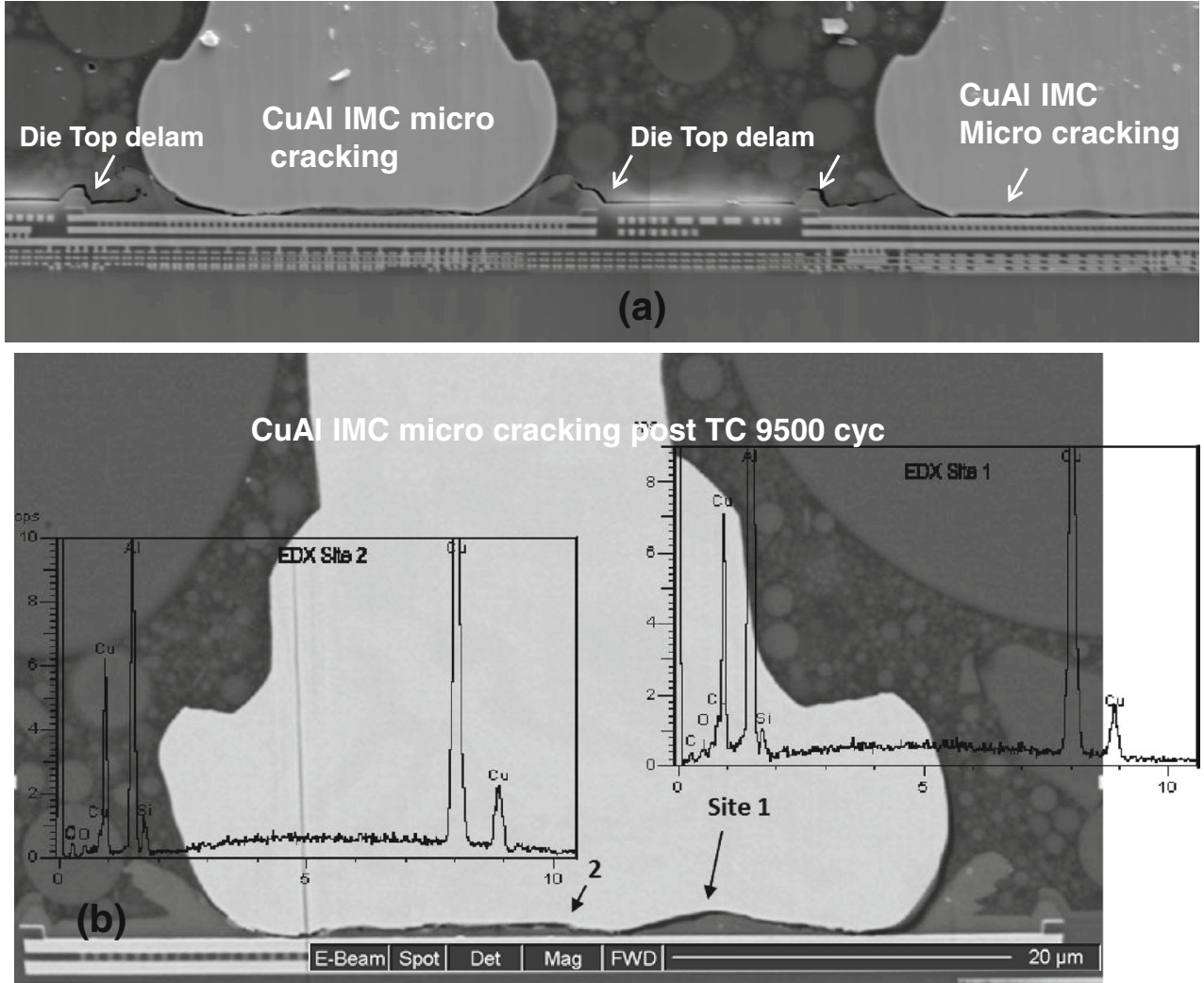

$\mathrm{Au}$ ball bond undergoes a slightly different corrosion mechanism in HAST or UHAST reliability stressing. Moisture in HAST or UHAST chamber will penetrate from the edge of $\mathrm{Au}$ ball bond after long hours of HAST and UHAST stressing. AuAl IMC will react with moisture and form $\mathrm{Al}_{2} \mathrm{O}_{3}$ and hydrogen outgassing (as shown in Eq. 3). Hydrogen gas evolution due to moisture in contact with intermetallics has been extensively documented and is one of the known causes of embrittlement [10]. Stress-induced microcracking will cause AuAl microcracking together with the formation of Kirkendall microvoiding which results in uneven AuAl IMC formation (refer Fig. 4). Lifted Au ball bond will occur after long hours of HAST or UHAST stress and this is typical wear out failure (as shown in Fig. 10).

$2 \mathrm{Au}_{4} \mathrm{Al}+3 \mathrm{H}_{2} \mathrm{O} \rightarrow \mathrm{Al}_{2} \mathrm{O}_{3}+8 \mathrm{Au}+6 \mathrm{H}$

Table 4 EDX analysis of failed $\mathrm{Cu}$ and $\mathrm{Au}$ ball bonds after TC 9,500 cycles

\begin{tabular}{lllllllll}
\hline Location & \multicolumn{7}{l}{ Element (atomic \%) } \\
\cline { 2 - 8 } & $\mathrm{Au}$ & $\mathrm{Cu}$ & $\mathrm{O}$ & $\mathrm{Al}$ & $\mathrm{Si}$ & $\mathrm{C}$ & $\mathrm{Cl}$ \\
\hline Au ball & 38.25 & - & 1.76 & 59.99 & - & - & - \\
Cu ball & - & 77.58 & 2.11 & 13.74 & 3.74 & 2.83 & \\
\hline
\end{tabular}

$\mathrm{Au}$ and $\mathrm{Cu}$ ball bond microcracking in HTSL

$\mathrm{Au}$ ball bond is found with higher IMC growth rate at least $5 \times$ compared to $\mathrm{Cu}$ ball bond in HTSL aging test $[1,25]$. Hence, there is slightly different HTSL failure mechanism after long duration of aging stress in $\mathrm{Au}$ and $\mathrm{Cu}$ ball bonds. Both $\mathrm{CuAl}$ and $\mathrm{AuAl}$ IMCs are formed in long hours of HTSL test except more uniform AuAl IMC formation compared to $\mathrm{CuAl}$. Thicker $\mathrm{CuAl}$ IMC is formed at the edge of $\mathrm{Cu}$ ball bond (see Figs. 2 and 7c). AuAl IMC is observed with more uniform and thicker (as indicated in Fig. 8) but Kirkendall microvoiding will occur which might induce AuAl IMC microcracking (Fig. 11b). HTSL wear out opens occur as lifted ball bonds for both $\mathrm{Au}$ and $\mathrm{Cu}$ balls except with Kirkendall microvoiding in $\mathrm{Au}$ ball bonds (Fig. 11a, b, respectively).

$\mathrm{Au}$ and $\mathrm{Cu}$ ball bond microcracking in $\mathrm{TC}$

Table 6 tabulates coefficient of thermal expansion (CTE) for materials used in package bills of materials in FBGA 64. The mismatch in CTE between $\mathrm{Cu}$ (17.8 ppm $/{ }^{\circ} \mathrm{C}$ ) and $\mathrm{Au}$ ball bond $\left(14.2 \mathrm{ppm} /{ }^{\circ} \mathrm{C}\right)$ to the silicon die $\left(3.0 \mathrm{ppm} /{ }^{\circ} \mathrm{C}\right)$ induced different thermal expansions and contraction rates in the temperature cycling test. The CTE mismatch between $\mathrm{Au}$ and $\mathrm{Cu}$ ball 
Fig. $7 \mathrm{Cu}$ ball bond IMC microcracking is found after HTSL 3,500 h of stressing (a, b). EDX area scan reveals presence of $\mathrm{O}, \mathrm{Al}, \mathrm{Si}$, and $\mathrm{Cu}$ elements at the edge of failed $\mathrm{Cu}$ ball bond. No signature of halide element such as $\mathrm{Cl}(\mathbf{c})$
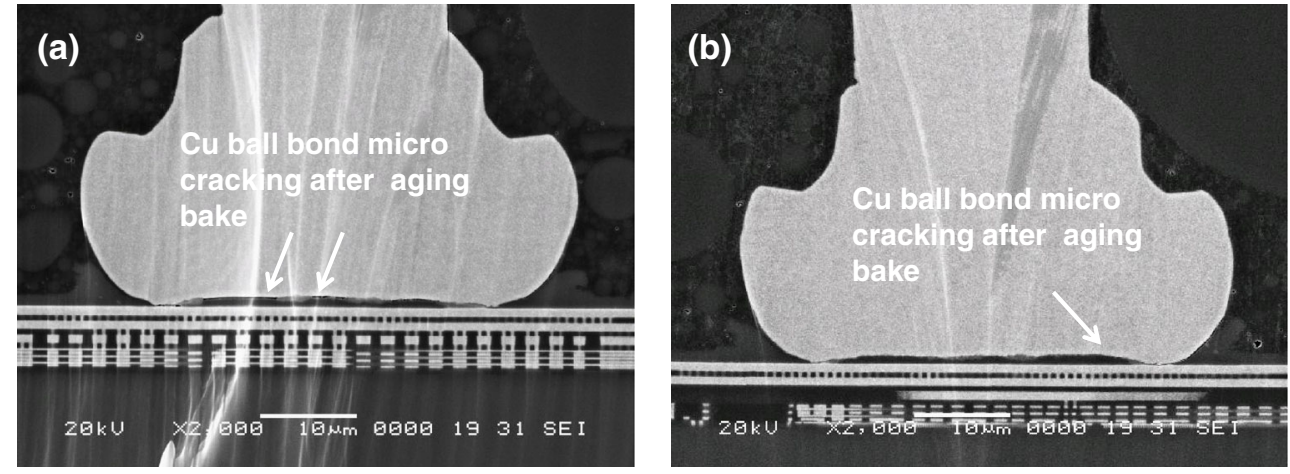

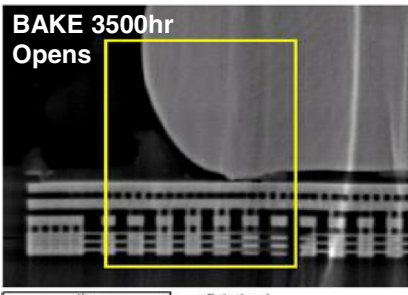

(c)

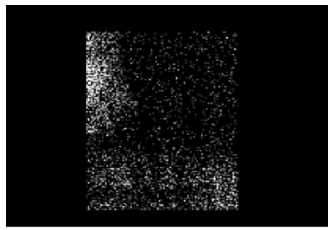

Oxygen ka1_2

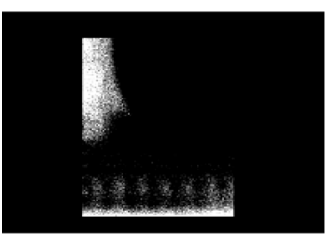

Silicon Ka

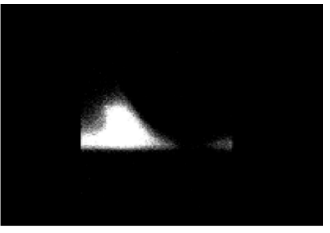

Alurninum Ka1

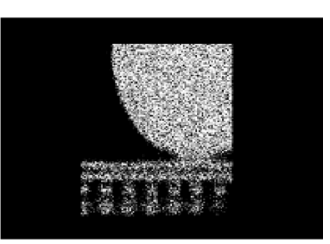

Copper ka1 bonds with Al bondpad of silicon die will impose different thermal expansion rates during hot cycles $\left(150{ }^{\circ} \mathrm{C}\right)$ and contraction rates during cold cycles $\left(-40^{\circ} \mathrm{C}\right)$. IMC formation initiated at the edge of the ball bond (due to the ball bond pressing force by bonding capillary) and microcracking will be induced after long cycles of thermal cycling effects. The microcracking occurs in between ball bond IMC (as shown in Fig. 12). This predicted TC mechanism also correlated to SEM images as indicated in Fig. 12.
Fig. 8 Au ball bond with uneven $\mathrm{AuAl}$ IMC formation and Kirkendall microvoiding are found along the $\mathrm{Au}$ ball bond after HTSL $3,000 \mathrm{~h}$ at $150^{\circ} \mathrm{C}$ aging condition. Hairline cracking is observed along the Kirkendall microvoiding region
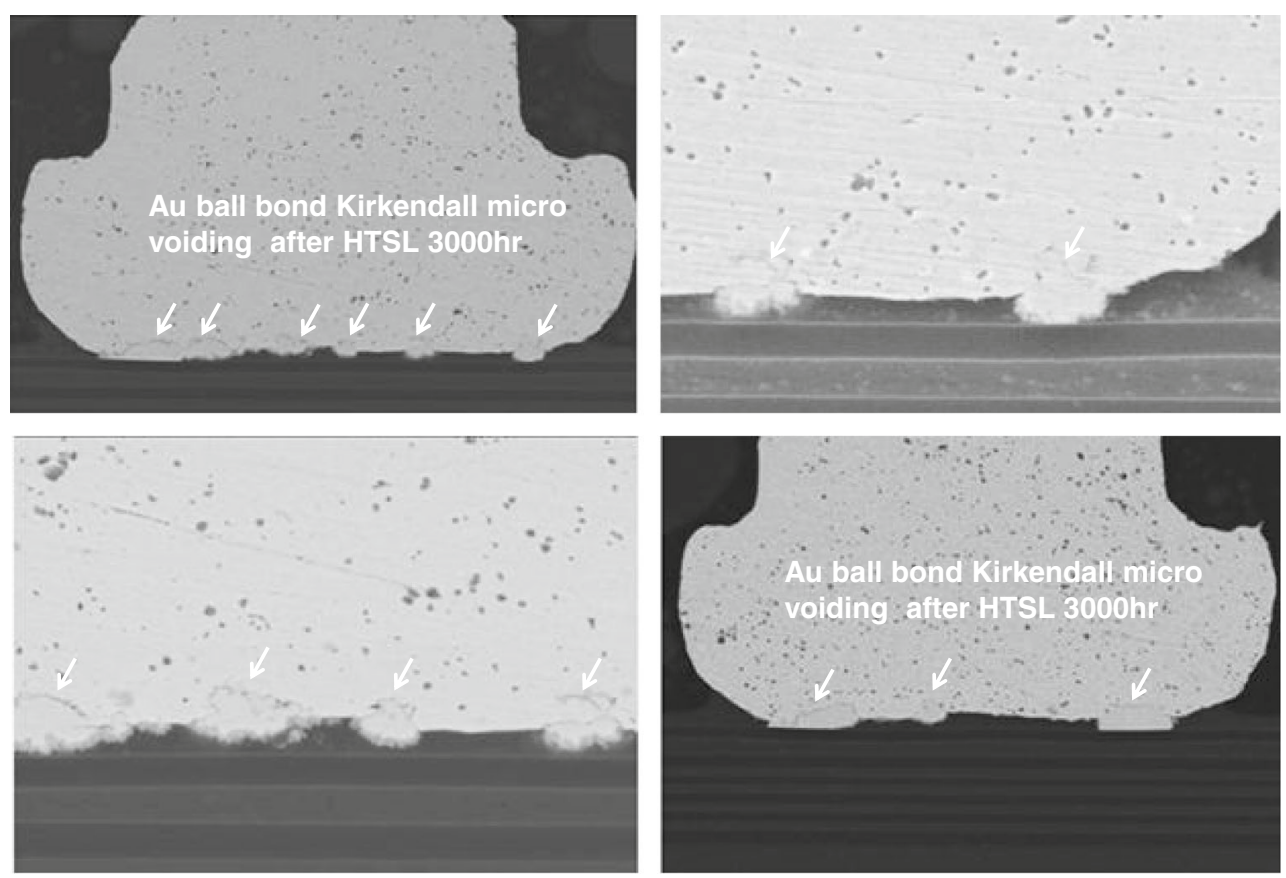
Table 5 EDX analysis of failed $\mathrm{Cu}$ and $\mathrm{Au}$ ball bonds after HTSL $3,500 \mathrm{~h}$

\begin{tabular}{lllllll}
\hline Location & \multicolumn{2}{l}{ Element (atomic \%) } & & & \\
\cline { 2 - 7 } & $\mathrm{Au}$ & $\mathrm{Cu}$ & $\mathrm{O}$ & $\mathrm{Al}$ & $\mathrm{Si}$ & $\mathrm{Cl}$ \\
\hline Au ball & 48.65 & - & 0.97 & 50.38 & - & - \\
$\mathrm{Cu}$ ball & - & 77.58 & 2.11 & 13.74 & 3.74 & - \\
\hline
\end{tabular}

Extended reliability analysis of $\mathrm{Au}$ and $\mathrm{Cu}$ ball bonds

\section{Humidity reliability analysis (UHAST)}

All package reliability plots belong to wear out reliability mode in bathtub curve since its shape parameter ( $(B)$ is more than 1.0. Au ball bonds show better UHAST package reliability performance with higher mean-time-to failure hours $\left(t_{50}\right)$ and characteristics life $\left(t_{63.2}, \eta\right)$ in UHAST reliability plot (fitted to Weibull distribution) compared to $\mathrm{Cu}$ ball bonds. Figure 13 illustrates a $\mathrm{Cu}$ ball bond with lower package reliability margin and usually more susceptible to $\mathrm{Cu}$ moisture corrosion test under UHAST condition. This has been reported in our previous literature works $[8$, 25-27, 31]. $\mathrm{Cu}$ ball bond has a layer of Pd coated on low-corrosive resistance $\mathrm{Cu}$ wire which inhibits moisture ball bond corrosion in UHAST conditions $\left(130{ }^{\circ} \mathrm{C}\right.$, $85 \% \mathrm{RH})$. However, Au wire is well known with corrosion resistant material and shows higher hours-tofailure in UHAST wear out reliability plot (Fig. 13).

\section{Dry environmental reliability analysis (TC)}

$\mathrm{Cu}$ ball bonds is found with higher mean-time-to failure hours $\left(t_{50}\right)$ and characteristics life $\left(t_{63.2}\right)$ in TC reliability plot (fitted to Weibull distribution), as indicated in Fig. 14. Apparently, $\mathrm{Cu}$ performs well under dry conditions in the TC cycling test $\left(-40{ }^{\circ} \mathrm{C}\right.$ to $\left.150{ }^{\circ} \mathrm{C}\right)$. In this case, we observe $\mathrm{Cu}$ ball bonds withstand higher cycle-to-failure compared to $\mathrm{Au}$ ball bonds in TC stress test conditions.
Fig. 9 Proposed $\mathrm{CuAl}$ IMC corrosion mechanism on $110 \mathrm{~nm}$ device FBGA 64 package after extended hours of biased HAST or unbiased HAST stressing [31]
Fig. 10 Proposed AuAl IMC Kirkendall microvoiding mechanism and induced opens after long aging hours on $110 \mathrm{~nm}$ device FBGA 64 package [31]

\section{Cu Bond HAST/ UHAST Corrosion Prediction}

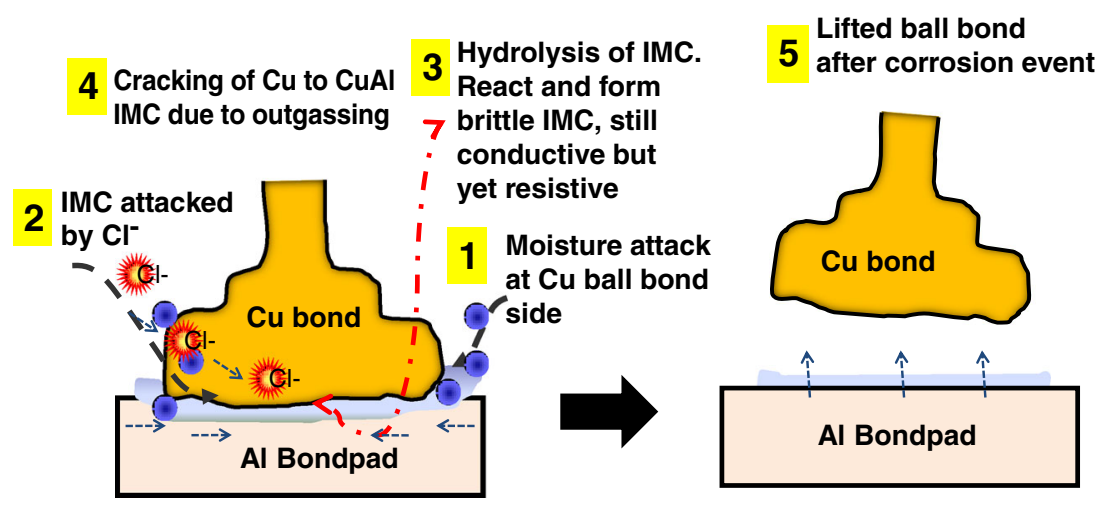

\section{Au Bond HAST Corrosion Prediction}

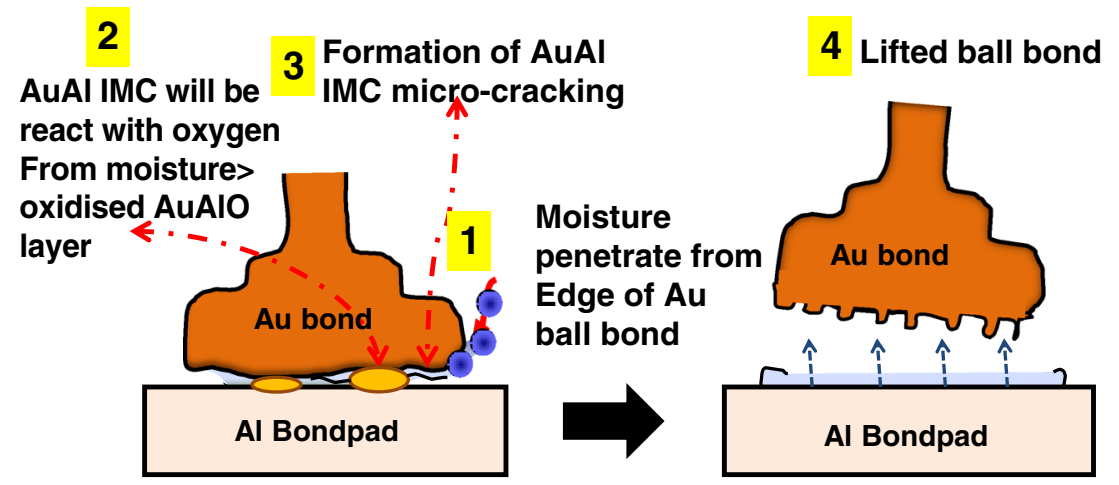


Fig. 11 Schematic representation of $\mathrm{Cu}$ ball bond microcracking after long hours of HTSL stressing (a) and Kirkendall microvoiding as a function of aging hours in $\mathrm{Au}$ ball bond (b)

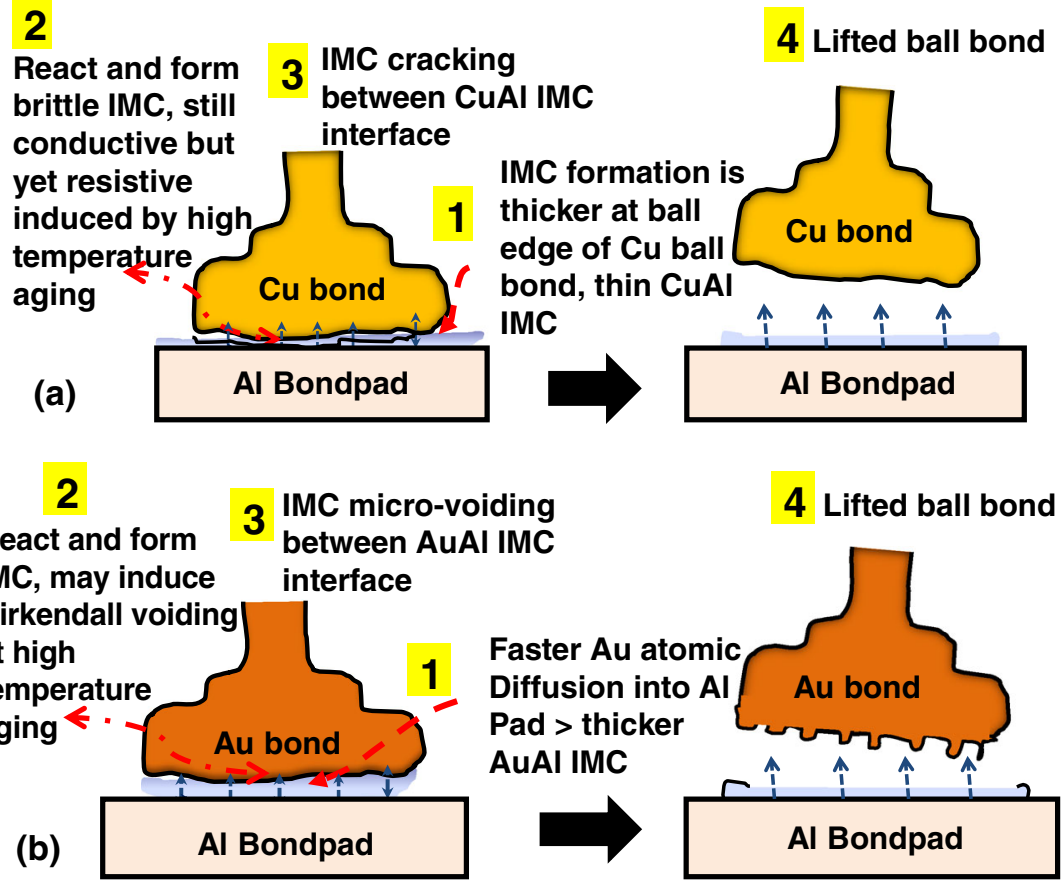

\section{Summary and conclusions}

Table 6 Key material characteristics of epoxy mold compound (EMC) A and $\mathrm{B}$

\begin{tabular}{lll}
\hline Material & Units & CTE (coefficient of thermal expansion) \\
\hline $\mathrm{Au}$ & $\mathrm{ppm} /{ }^{\circ} \mathrm{C}$ & 14.2 \\
$\mathrm{Cu}$ & $\mathrm{ppm} /{ }^{\circ} \mathrm{C}$ & 17.8 \\
$\mathrm{Silicon}$ & $\mathrm{ppm} /{ }^{\circ} \mathrm{C}$ & 3.0 \\
$\mathrm{Al}$ & $\mathrm{ppm} /{ }^{\circ} \mathrm{C}$ & 22.2 \\
\hline
\end{tabular}

The purpose of this research is to investigate and understand the microstructural evolution of $\mathrm{Au}$ and $\mathrm{Cu}$ ball bonds in extended reliability stressing such as HAST, UHAST, TC, and HTSL. To achieve this goal, both $\mathrm{AuAl}$ and $\mathrm{CuAl}$ intermetallic growth was studied at elevated temperatures in HTSL. In our study, respective failure mechanisms of copper and gold ball bonds carrion under HAST and UHAST, ball bond lifting in TC and HTSL have been analyzed and proposed. The evolution of surface morphology, including copper and gold ball bond microcracking, gold ball bond Kirkendall
Fig. 12 Proposed $\mathrm{Cu}$ ball bond microcracking induced by different rate of contraction and expansion between $\mathrm{Cu}$ bond and silicon die after extended temperature cycling

\section{Cu Bond TC Lifted Ball Prediction}

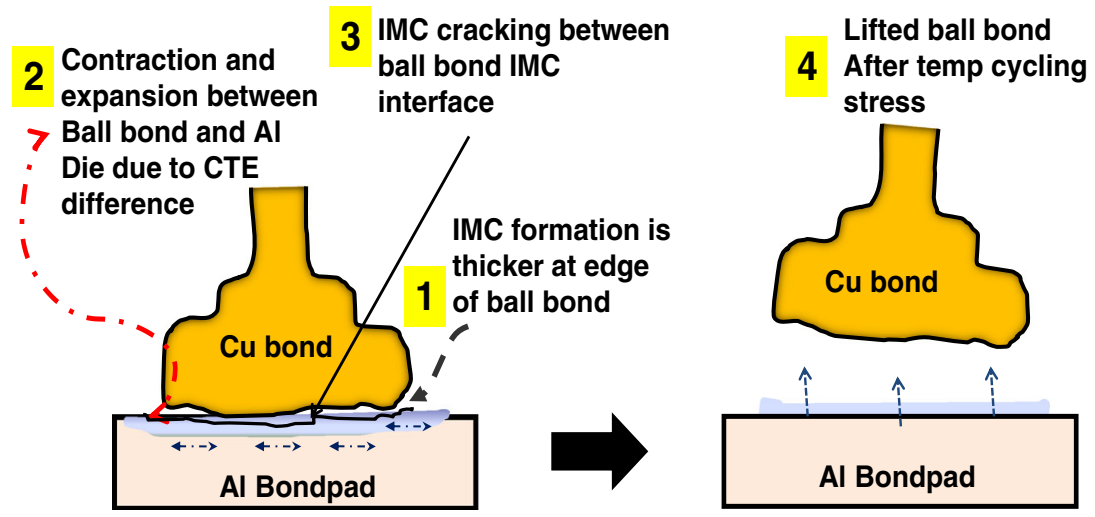




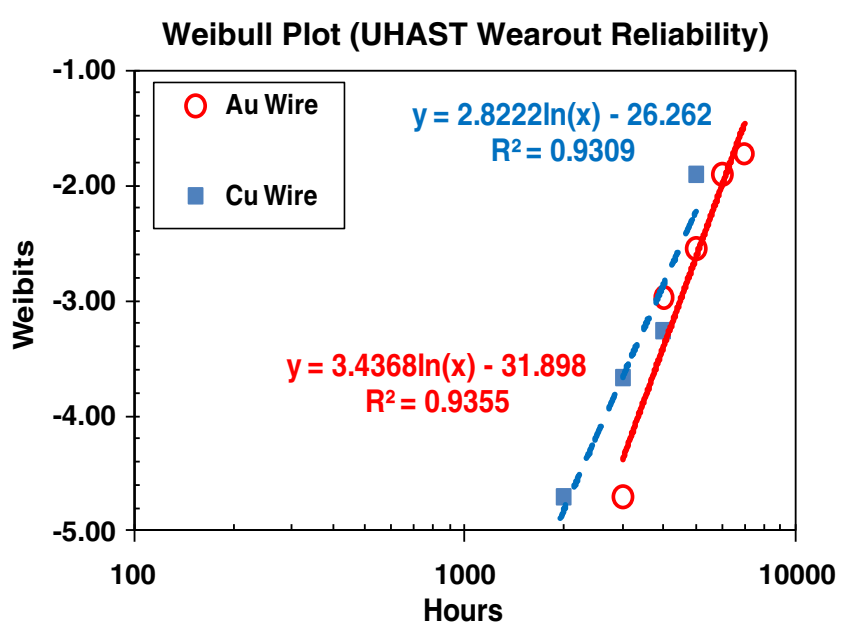

Fig. 13 Obtained Weibull plotting of $\mathrm{Au}$ and $\mathrm{Cu}$ ball bonds in unbiased HAST reliability stress with different epoxy mold compounds (EMC) $[26,31]$

microvoiding and IMC formation, was studied in FBGA package with copper and gold ball bonds during various reliability stresses. Au ball bonds show superior extended UHAST reliability than $\mathrm{Cu}$ ball bonds for both mold compounds A and B (see Fig. 13). This could be due to $\mathrm{Au}$ is more stable and higher corrosion resistance under moisture UHAST conditions compared to $\mathrm{Cu}$ ball bonds. We observed $\mathrm{Cu}$ ball bonds with higher TC extended reliability performance (higher $t_{\text {first }}, t_{50}$, and $t_{63.2}$ ) compared to Au ball bonds in FBGA 64 package of both mold compounds A and B (Fig. 14). The effect of wire type is not the key factor affecting the TC reliability performance but we observed higher extended reliability performance in $\mathrm{Cu}$ ball bonds compared to $\mathrm{Au}$ ball bonds.

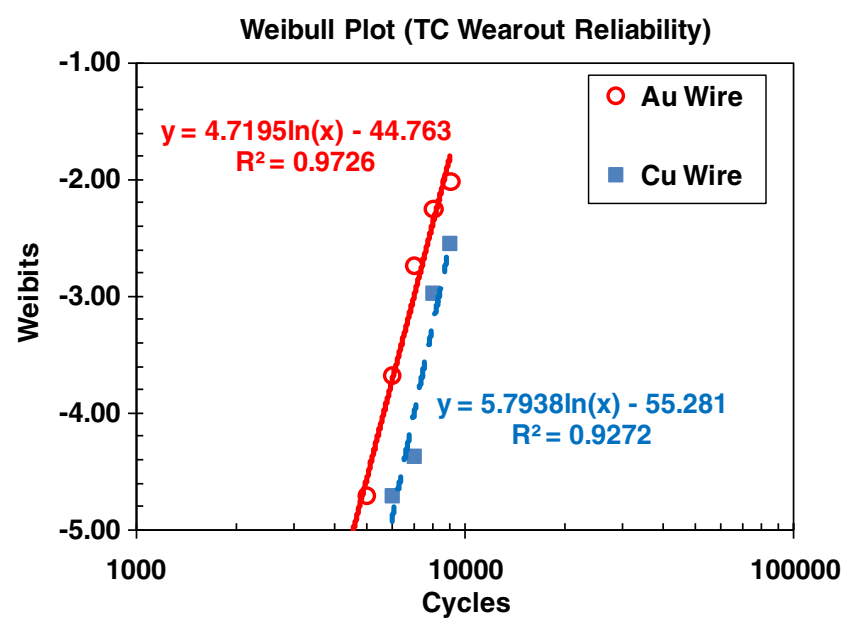

Fig. 14 Obtained Weibull plotting of $\mathrm{Au}$ and $\mathrm{Cu}$ ball bonds in extended TC reliability stress with different epoxy mold compounds (EMC) $[26,31]$
Acknowledgement The authors would like to take this opportunity to thank Spansion management for their management support for the paper publication.

Open Access This article is distributed under the terms of the Creative Commons Attribution License which permits any use, distribution, and reproduction in any medium, provided the original author(s) and the source are credited.

\section{References}

1. Harman GG (1999) Wirebonding in microelectronic: materials, processes, reliability and yield, 2nd edn. McGraw Hill, New York

2. Chauhan P, Zhong ZW, Pecht M (2014) Copper wire bonding, 1st edn. Springer, New York

3. Chauhan P, Zhong ZW, Pecht M (2013) Copper wire bonding concerns and best practices. J Electron Mater. doi:10.1007/s11664-0132576-1

4. Schneider-Ramelow M, Geißler U, Schmitz S et al (2013) Development and status of $\mathrm{Cu}$ ball/wedge bonding in 2012. J Electron Mater 42:558-595. doi:10.1007/s11664-012-2383-0

5. Appelt BK, Tseng A, Chen C-H, Lai Y-S (2011) Fine pitch copper wire bonding in high volume production. Microelectron Reliab 51: $13-20$

6. Gan CL, Ng EK, Chan BL, Hashim U (2012) Technical barriers and development of cu wirebonding in nanoelectronics device packaging. J Nanomater 2012:1-7. doi:10.1155/2012/173025

7. Gan CL, Ng EK, Chan BL, T Kwuanjai, S Jakarin, Hashim U (2012) Wearout reliability study of cu and au wires used in flash memory fineline BGA package, 2012 I.E. 7th Int. Microsystems, Packag. Technol. Conf. pp 494-497

8. Gan CL, Toong TT, Lim CP, Ng CY (2010) Environmental friendly package development by using copper wirebonding. 34th IEEE CPMT IEMT, Malacca, 2010, pp. 1-5

9. Zhong ZW (2009) Wire bonding using copper wire. Microelectron Int 26:10-16

10. Breach CD (2010) What is the future of bonding wire? Will copper entirely replace gold? Gold Bull 43:150-168

11. Murali S, Srikanth N, Wong YM, Vath CJ (2006) J Mater Sci 42:615623

12. Karpel A, Gur G, Atzmon Z, Kaplan WD (2007) Microstructural evolution of gold-aluminum wire-bonds. J Mater Sci 42:2347-2357

13. Drozdov M, Gur G, Atzmon Z, Kaplan WD (2008) Detailed investigation of ultrasonic Al-Cu wire-bonds: I Intermetallic formation in the as-bonded state. J Mater Sci 43:6029-6037

14. Drozdov M, Gur G, Atzmon Z, Kaplan WD (2008) Detailed investigation of ultrasonic Al-Cu wire-bonds: II. Microstructural evolution during annealing. J Mater Sci 43:6038-6048

15. Xu C, Breach CD, Sritharan T et al (2004) Oxidation of bulk $\mathrm{Au}-\mathrm{Al}$ intermetallics. Thin Solid Films 462-463:357-362

16. Xu H, Liu C, Silberschmidt VV et al (2009) A re-examination of the mechanism of thermosonic copper ball bonding on aluminium metallization pads. Scr Mater 61:165-168

17. Xu H, Liu C, Silberschmidt VV et al (2011) Behavior of aluminum oxide, intermetallics and voids in $\mathrm{Cu}-\mathrm{Al}$ wire bonds. Acta Mater 59: 5661-5673

18. Zeng Y, Bai K, Jin H (2013) Thermodynamic study on the corrosion mechanism of copper wire bonding. Microelectron Reliab. In Press

19. Gan CL, Ng EK, Chan BL, Hashim U (2012) Reliability challenges of $\mathrm{Cu}$ wire deployment in flash memory packaging. 2012 I.E. 7th Int. Microsystems, Packag. Technol. Conf. pp 498-501

20. Tan C, Daud A, Yarmo M (2002) Corrosion study at $\mathrm{Cu}-\mathrm{Al}$ interface in microelectronics packaging. Appl Surf Sci 191:67-73 
21. Uno T (2011) Microelectron reliab 51:148-156

22. Yamaji Y, Hori M, Ikenosako H, et al. (2011) IMC study on $\mathrm{Cu}$ wirebond failures under high humidity conditions. 2011 I.E. 13th Electron. Packag. Technol. Conf. IEEE, pp 480-485

23. Su P, Seki H, Ping C, et al. (2013) Effects of reliability testing methods on microstructure and strength at the $\mathrm{Cu}$ wire-Al pad interface. 2013 I.E. 63rd Electron. Components Technol. Conf., pp 179-185

24. Lu YH, Wang YW, Appelt BK, Lai YS, Kao CR (2011) Growth of $\mathrm{CuAl}$ intermetallic compounds in $\mathrm{Cu}$ and $\mathrm{Cu}(\mathrm{Pd})$ wire bonding. 2011 I.E. Electron. Components Technol. Conf., pp 1481-1488

25. Gan CL, Ng EK, Chan BL et al (2012) Wearout reliability and intermetallic compound diffusion kinetics of $\mathrm{Au}$ and $\mathrm{PdCu}$ wires used in nanoscale device packaging. J Nanomater 2012:1-9

26. Gan CL, Hashim U (2013) Reliability assessment and mechanical characterization of $\mathrm{Cu}$ and $\mathrm{Au}$ ball bonds in BGA package. J Mater Sci Mater Electron 24:2803-2811

27. Gan CL, Francis C, Chan BL, Hashim U (2013) Extended reliability of gold and copper ball bonds in microelectronic packaging. Gold Bull 46:103-115

28. Gan CL, Hashim U (2013) Superior performance and reliability of copper wire ball bonding in laminate substrate based ball grid array. Microelectron Int 30:169-175
29. Gan CL, Hashim U (2013) Comparative reliability studies and analysis of $\mathrm{Au}, \mathrm{Pd}$-coated $\mathrm{Cu}$ and $\mathrm{Pd}$-doped $\mathrm{Cu}$ wire in microelectronics packaging. PLoS One 8:1-8

30. Gan CL, Francis C, Chan BL, Hashim U (2014) Future and technical considerations of gold wirebonding in semiconductor packaging - a technical review. Microelectron. Int. 31. In Press

31. Gan CL, Francis C, Chan BL, Hashim U (2013) Effects of wire type and mold compound on wearout reliability of semiconductor flash fineline BGA package. IEEE 8th Int. Microsystems, Packag. Assem. Circuits Technol. Conf. pp 297-301

32. Yu C-F, Chan C-M, Chan L-C, Hsieh K-C (2011) Cu wire bond microstructure analysis and failure mechanism. Microelectron Reliab 51:119-124

33. Mc Pherson JW (2013) Reliability physics and engineering: time-tofailure modeling, 2nd edn. Springer, New York

34. Gan CL, Hashim U (2013) Reliability assessment and activation energy study of $\mathrm{Au}$ and $\mathrm{Pd}$-coated $\mathrm{Cu}$ wires post high temperature aging in nanoscale semiconductor packaging. J Electron Packag 135: 021010

35. JEDEC IPC STD 020 (2008) Moisture/reflow sensitivity classification for nonhermetic solid state surface mount devices 